compression: Report of a case. J Can Assoc Radiol 1968;19:192-4.

"Urso S, Carfagni A, Amorese V. Vertebral compression syndrome in multiple exostoses. Ital J Orth Traumatol 1977;3:333-40.

12 Petit-Dutaillis D, Lereboullet J. Paraplégie par fibrochondrome des vertebres dorsales supérieures ches une malade atteinte de maladie ostéogénique. Bull Soc Chir Paris 1934;60:694-6.

${ }^{13}$ Larson NE, Dodge HW, Rushton JG, Dahlin DC. Hereditary multiple exostoses with compression of the spinal cord. Proc Staff Meet Mayo Clin 1957;32:728-34.

${ }^{14}$ Adam H, Morin P. Compression medulaere par eostose au cours d'une maladie exostosante. Press Med 1966;74:660.

${ }^{15}$ Signargout J, Guegan Y, Lemare B, Simon J. Les paraplégies de la maladie des exostoses multiple. J Radiol Electrol Med Nucl 1973;54:403-7.

${ }^{16}$ Chiurco AA. Multiple exostoses of bone with fatal spinal cord compression. Neurology (Minneap) 1970;20:275-8.

${ }^{17}$ Singh DS, Rao SS, Sharma S, Srivastava KK, Yadav SS. Cervical cord compression from multiple hereditary exostoses. J Asso Phys Ind 1980;28:5335-7.

${ }^{18}$ Oberndorf CP. A case of multiple exostoses coupled with syringomyeli. NY Med J 1910;91:479-83.

${ }^{19}$ Carmel PW, Crammer FJ. Cervical cord compression due to exostoses in a patient with hereditary multiple exostoses. J Neurosurg 1968;28:500-3.

${ }^{20}$ Vinstein AL, Franken EA. Hereditary multiple exostoses: report of a case with spinal cord compression. Am J Roentgenol Radium Ther Nucl Med 1971;112:405-7.

${ }^{21}$ Madigan R, Worral T, McClain E. Cervical cord compression in hereditary multiple exostoses. J Bone Joint Surg 1974;56A:401-4.

${ }^{22}$ Slepian A, Hamby WB. Neurological complications associated with hereditary deforming chondrodysplasia: Review of the literature and a report on two cases occurring in the same family. J Neurosurg 1951;8:52935.

${ }^{23}$ Reid J. A case of disease of the spinal cord from an exostosis of the second cervical vertebra. Mon J Med Science 1843;3:194-8. As cited by Madigan et al.

\section{Alcaptonuria with Seizures}

Sir: Alcaptonuria, an inherited metabolic disorder of tyrosine metabolism presents in childhood without any symptoms other than the complaint of darkening of urine on standing. We wish to report the occurrence of seizures in one of our cases of alcaptonuria.

An 8-year-old school boy (A) with normal birth history and normal developmental milestones presented with occasional seizures. The first fits of generalised tonicclonic type occurred on the 4th day of life and thereafter attacks occurred approximately once a year. A casual mention was made by his parents that his urine became dark on standing and his undergarments were stained, so alcaptonuria was suspected. There were no symptoms of joint pain or back-ache. His intelligence was normal. Neurological examination revealed no abnormality and clinical, radiological and ECG examination of the heart were non-contributory. On enquiring into the family history, it was found that he had four sisters and a brother. His 23 year-old eldest sister (AL) had also a similar darkening of her urine on standing, and darkish triangular pigmentation was seen in the sclerae of her eyes. Neither she nor the other sibs had convulsions or joint pains.

Routine investigations, including total and differential WBC counts, haemoglobin content, ESR, blood sugar, urea and cholesterol were normal in both $\mathrm{A}$ and $\mathrm{AL}$. CT head scan revealed no abnormality in A. The urine of both the sibs showed no albumin, sugar or deposits on preliminary examination but did turn darkish brown on standing. The presence of homogentisic acid in the urine of $A$ and $A L$ was proved by paper chromatography. The EEG in both cases showed evidence for epileptic activity. There were clear-cut bilaterally synchronous 3 to $3 \frac{1}{2} \mathrm{~Hz}$ high voltage slow wave bursts appearing rhythmically, with independent discrete and synchronous spike discharges over both hemispheres in the EEG of the boy; the EEG of the asymptomatic sister also showed evidence of epileptic activity in the form of bilaterally synchronous spike discharges. The EEGs of the other sibs were normal.

The presence of alcaptonuria and seizures in the two cases described may be a fortuitous coexistence. However, only the two sibs (out of the six) who had alcaptonuria had epileptic discharges on the EEG, with one of them (A) also manifesting overt convulsions. No one else suffered from seizures in the family and the EEGs of the sibs with no alcaptonuria were normal. The association of seizures with certain types of disordered amino acid metabolism is well known. The commonest situation is probably phenylketonuria, where EEG changes have been studied in detail. ${ }^{1}$ It is hypothesised that damage to the brain occurs very early in life when the immature brain is presented with abnormal patterns of amino acids from which it cannot construct its essential and permanent components. ${ }^{2}$ Cases of alcaptonuria picked up occasionally nowadays are not reported in the literature unless some remarkable or strange clinical features are present. In addition to the well known scleral pigmentation and ochronotic arthropathy that are the hallmarks of the full classical clinical presentation, a few rare features also have been reported. They include heart disease, ${ }^{34}$ prostatitis, ${ }^{5}$ renal stones, ${ }^{6}$ and "nephrosis". 7 So far, no case of alcaptonuria has been described with seizures; and this prompted us to report this association of alcaptonuria with seizures although the exact mechanism remains unclear.

PA BHASKAR, B NEELAKANDAN

Department of Neurology,

Thanjavur Medical College Hospital, Thanjavur, India.

\section{References}

' Gross PT, Berlow S, Schuett UE, Farriello RG. EEG in phenylketonuria. Arch Neurol 1981;38:122-6.

${ }^{2}$ Knox WE. Pathogenetic effects of elevated plasma phenylalamine in phenylketonuria. In: Folch-Pi J, ed. Chemical Pathology of the Nervous System. New York: Pergamon Press, 1961;32.

${ }^{3}$ Smith HP, Smith HP, Jr. Ochronosis: report of two cases. Ann Intern Med 1955;42:171.

${ }^{4}$ Lichenstein L, Kaplan L.Hereditary ochronosis pathological changes observed in two nec

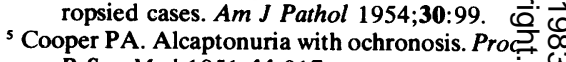
$R$ Soc Med 1951;44:917.

- Young HH. Calculi of the prostate associated with ochronosis and alcaptonuria. J Urol 1944;51:48.

Cooper JA, Moran TJ. Studies on ochronosis. AMA Arch Path 1957;64:46. 